\title{
Precipitation Behavior of the Topologically Close-Packed Phase in the DD5 Superalloy during Long-Term Aging
}

\author{
Guiqun Liu $\mathbb{D}^{1}{ }^{1}$ Xiaoli Zhang $\mathbb{D},{ }^{1}$ Xinyi Wang, ${ }^{2}$ and Yanxin Qiao $\mathbb{D}^{2}$ \\ ${ }^{1}$ College of Material Science and Engineering, North Minzu University, Yinchuan 750021, China \\ ${ }^{2}$ School of Materials Science and Engineering, Jiangsu University of Science and Technology, Zhenjiang 212003, China \\ Correspondence should be addressed to Xiaoli Zhang; xlzhang@alum.imr.ac.cn and Yanxin Qiao; yxqiao@just.edu.cn
}

Received 26 December 2019; Accepted 14 February 2020; Published 6 March 2020

Guest Editor: Zhiping Xiong

Copyright (c) 2020 Guiqun Liu et al. This is an open access article distributed under the Creative Commons Attribution License, which permits unrestricted use, distribution, and reproduction in any medium, provided the original work is properly cited.

\begin{abstract}
The precipitation behaviors of the topologically close-packed (TCP) phases in the bicrystal DD5 superalloy have been investigated. The results showed that the [001] crystallographic orientations are consistent with that of adjacent grains; however, the direction of the needle-like TCP phases is not consistent with that of the $\gamma$ phase channels. The angle between needle-like TCP phases and $\gamma$ phase channels is $45^{\circ}$, but the angle between the needle-like TCP phases of the adjacent grains is equal to the misorientation of the adjacent grains. Furthermore, during long-term aging, the needle-like TCP phases gradually decompose and transform into globular and short rod-like phases. The TCP phases precipitate preferentially in the dendrite. It is difficult to precipitate at the interdendrite/grain boundary, which is caused by the segregation of the constituent elements of the TCP phase to the dendrite.
\end{abstract}

\section{Introduction}

Superalloy is a kind of high-alloying iron-based, nickelbased, or cobalt-based metal material, which can withstand large complex stress above $600^{\circ} \mathrm{C}$ and has certain surface stability [1]. Nickel-based single-crystal superalloys have been widely used as jet engines and industrial gas turbine blades. In order to continuously improve its high temperature creep resistance, more and more refractory elements have been added to the superalloy. Presently, the known refractory elements such as $\mathrm{Cr}$, Mo, W, and Re are good creepstrengthening elements. In particular, Re is recognized as the alloy element with outstanding strengthening effect. However, the addition of excessive refractory elements will significantly reduce the stability of the alloy structure.

The addition of excessive alloy elements such as Cr, Mo, $\mathrm{W}$, and Re to the superalloy will cause the precipitation of intermetallic phases which have complex crystal structures rich in these refractory elements during long-term heat exposure or service. Because of their special dense structures, these phases are generally referred to as the topologically close-packed (TCP) phase [2]. The TCP phases of Ni-based single-crystal superalloys are $\sigma, \mu, \mathrm{P}$, and $\mathrm{R}[3,4]$. It is gener- ally accepted that the TCP phase will deteriorate the creep properties of the alloy. So how to avoid the precipitation of the TCP phase is an important aspect of alloy design. Only by knowing more about the precipitation rules and characteristics of the TCP phase, we can avoid the precipitation of the TCP phase reasonably and effectively, so as to better optimize the design of the alloy.

Frank and Kasper [5,6] first investigated the crystal structure characteristics of TCP phases and characterized the TCP phase by coordination polyhedron. These so-called Kasper polyhedrons have equilateral triangle surfaces and four atomic coordination numbers of $12,14,15$, and 16, but in practice, polyhedron surfaces often deviate from equilateral triangles [2]. The structure of the TCP phase is composed of pentagonal or hexagonal antiprism arranged side by side. The antiprism can usually be regarded as some simple structural units, and using these structural units to characterize the structure of the TCP phase will greatly simplify the process of analysis [7-9].

In the past few decades, the precipitation behavior of the $\mu$ phase has been extensively studied [10-15]. Many structural defects have been found in the $\mu$ phase in some superalloys or intermetallic compounds, such as stacking 
TABLE 1: The chemical compositions of the DD5 superalloy (wt\%).

\begin{tabular}{lccccccccr}
\hline $\mathrm{Cr}$ & $\mathrm{Co}$ & $\mathrm{Mo}$ & $\mathrm{W}$ & $\mathrm{Al}$ & $\mathrm{Ta}$ & $\mathrm{Re}$ & $\mathrm{Hf}$ & $\mathrm{C}$ & $\mathrm{Ni}$ \\
\hline 7.15 & 7.8 & 1.5 & 5.05 & 6.3 & 6.6 & 3 & 0.15 & 0.022 & $\mathrm{Bal}$. \\
\hline
\end{tabular}

faults, twin bands, microtwins, and second-phase symbiosis [11-13, 16-18]. However, there is little work on the detailed precipitation behavior of the $\mathrm{P}$ phase and $\mathrm{R}$ phase $[3,18-21]$.

In this paper, the TCP phase in the second-generation Ni-based superalloy DD5 is studied and the precipitation and evolution of the TCP phase are found and summarized. It provides evidence for further understanding the precipitation behavior and characteristics of the TCP phase in Ni-based single-crystal superalloys.

\section{Materials and Methods}

A second-generation single-crystal DD5 superalloy was used in this work. The chemical composition of the DD5 superalloy is listed in Table 1. The DD5 superalloy was produced by directional solidification and seeding so as to eliminate the effects of the grain boundary and crystallographic orientation on the TCP phase. In order to assure the directions of dendritic growth and thermal gradient to be accordant, the [001] direction of two seeds was aligned to the growth direction. The misorientation of the $[010] /[100]$ direction of two seeds was about $20^{\circ}$. Since the [001] direction of the seed is parallel to the primary dendrites of the seed and the $[010] /[100]$ direction of the seed is parallel to the secondary dendrites of the seed, the primary dendrites of two seeds are parallel to each other and parallel to the sample axis. The angle between the secondary dendrite arms of two seeds is about $20^{\circ}$. The dimension of the specimen was in size of $10 \times 10 \times 300 \mathrm{~mm}$.

A Bridgman high-rate solidification (HRS) furnace $[22,23]$, modified with two hot zones (upper zone and lower zone), was used in this study. The ceramic model was mounted on the water-cooled copper chill plate. The temperatures of the upper zone and lower zone were $1480^{\circ} \mathrm{C}$ and $1580^{\circ} \mathrm{C}$, respectively. The master alloy ingot was heated to $1580^{\circ} \mathrm{C}$ and kept at the temperature for $5 \mathrm{~min}$. Subsequently, the molten alloy was poured into the preheated mold. To ensure the system to attain a thermal equilibrium, casting samples were directionally solidified after $10 \mathrm{~min}$ of the pouring and pulled down in a withdrawal speed of $6 \mathrm{~mm} / \mathrm{min}$. When the temperature of the casting samples dropped to room temperature, the ceramic shell was broken and the bicrystal DD5 samples were taken out.

To determine the location of the grain boundary of the bicrystal DD5, all samples were macroetched with a mixture of $\mathrm{HCl}$ and $\mathrm{H}_{2} \mathrm{O}_{2}$ (volume ratio $5: 1$ ). Subsequently, the misorientation of the bicrystal DD5 superalloy was examined by the Electron Back Scattered Diffraction (EBSD) technique in a Scanning Electron Microscope (SEM). After microetching in a mixture of $100 \mathrm{ml} \mathrm{HCl}, 100 \mathrm{ml} \mathrm{H}_{2} \mathrm{O}, 5 \mathrm{ml} \mathrm{H}_{2} \mathrm{SO}_{4}$, and $2 \mathrm{~g} \mathrm{CuSO}_{4}$, the dendrite structure was observed using an optical microscope (OM). Finally, the TCP phase was observed by a SEM. The angle of $\gamma$ (needle-like TCP)

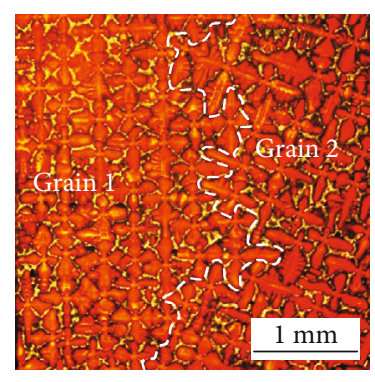

(a)

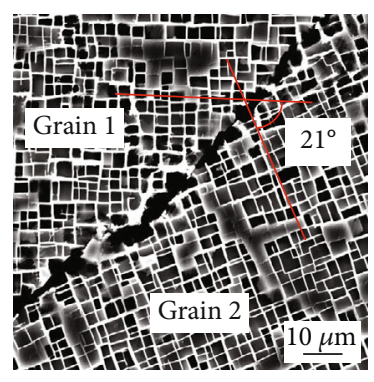

(b)
FIgURE 1: (a) Metallographic micrograph of as-cast bicrystal specimen and (b) SEM micrograph of the microstructure after standard heat treatment.

phases between two grains was measured by the analysis software of Image-Pro Plus.

To study the element segregation of as-cast DD5, the concentrations of each chemical element in dendrite and interdendrite were measured three times by the Electron Probe Micro Analyzer (EPMA). Then, the average value of the three measurements was taken. The segregation ratio was the average concentration of every element at dendrite divided by that at interdendrite.

The vacuum heat treatment of the bicrystal DD5 was as follows: $1310^{\circ} \mathrm{C} / 2 \mathrm{~h}$, air cooling; $1130^{\circ} \mathrm{C} / 4 \mathrm{~h}$, air cooling; and $900^{\circ} \mathrm{C} / 16 \mathrm{~h}$, air cooling. The long-term aging was $950^{\circ} \mathrm{C}$ for $100 \mathrm{~h}, 500 \mathrm{~h}, 1000 \mathrm{~h}$, and $2000 \mathrm{~h}$.

\section{Results and Discussions}

The cross-sectional microstructure of as-cast bicrystal DD5 is shown in Figure 1(a). It is the typical dendritic structure of the $<001>$ direction in grains 1 and 2, and the "white phase" of the interdendritic region is $\gamma / \gamma^{\prime}$ eutectic. The white dotted line between the two grains is the grain boundary. The angle between the secondary dendritic arms of both sides against the grain boundary is about $21^{\circ}$.

The cross-sectional microstructure of as-cast DD5 after vacuum heat treatment is shown in Figure 1(b). In grains 1 and 2, the white channel is the $\gamma$ phase and the black cube phase is the $\gamma^{\prime}$ phase. The $\gamma / \gamma^{\prime}$ eutectic at the grain boundary has completely disappeared, and the irregular block-like black $\gamma^{\prime}$ phases appear. It is worth noting that the direction of the white $\gamma$ phase in each grain is consistent with that of the secondary dendrite arm in Figure 1(a), and the angle between the two grains is about $21^{\circ}$. In other words, under the condition that the [001] crystallographic orientation of the adjacent grains is the same, the angle between the phase channels of the adjacent grains is consistent with that between the secondary dendritic arms of the adjacent grains.

The precise misorientation of the two grains in Figure 1 is shown in Figure 2. The precise misorientation of the two grains is $21^{\circ}$. This is in good agreement with the conclusion obtained from Figure 1. When the [001] crystallographic orientation of the adjacent grains is the same, the misorientation of two adjacent grains is equal to the angle between the $\gamma$ 


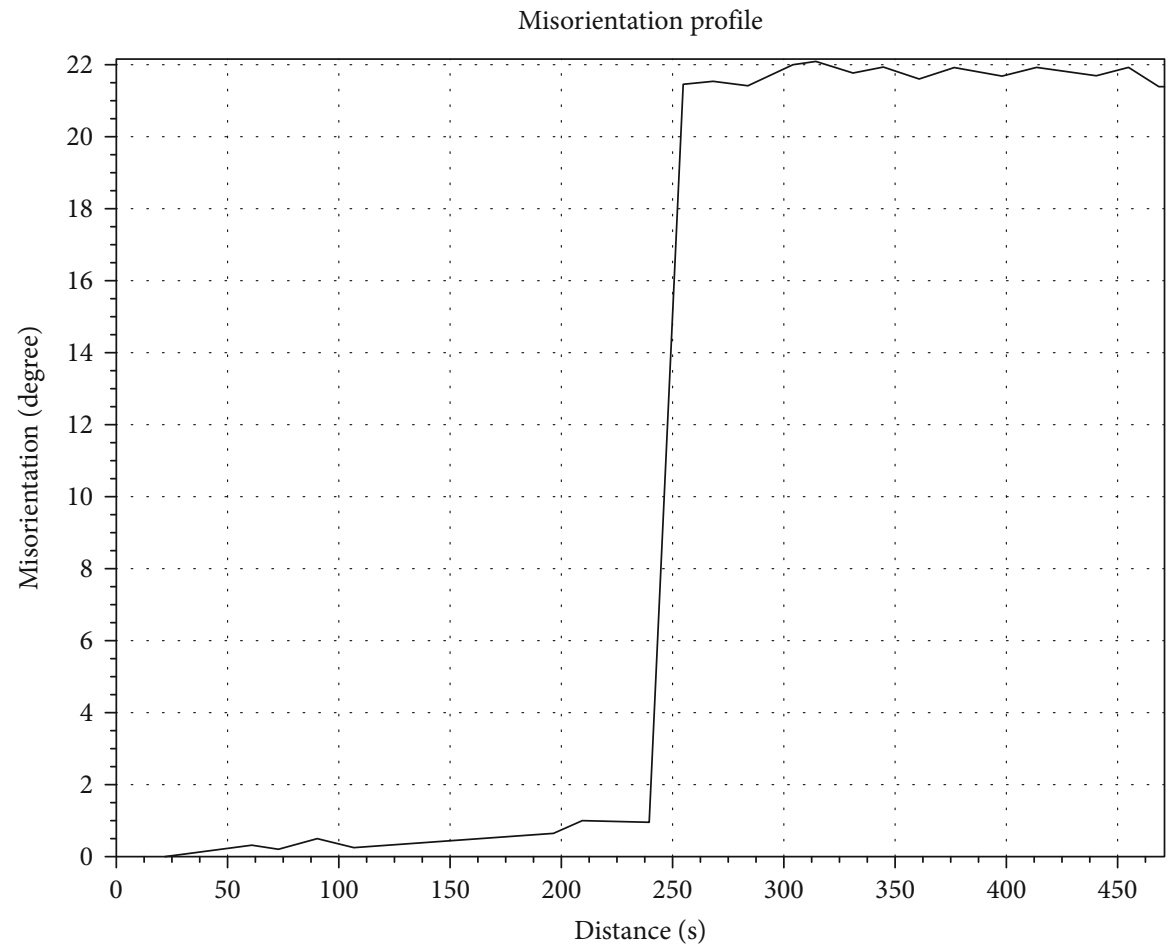

FIGURE 2: Misorientation of the as-cast bicrystal DD5 specimen measured by the line scanning of EBSD.

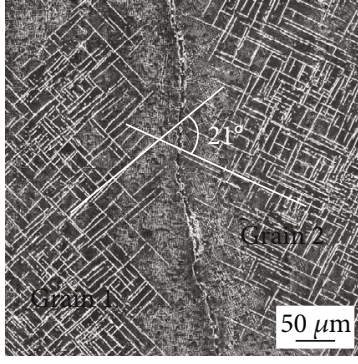

(a)

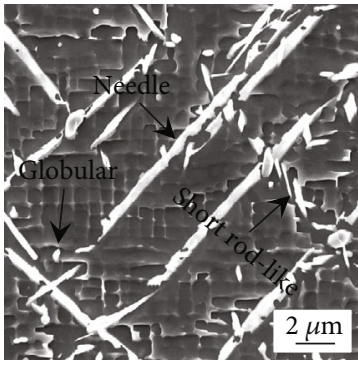

(b)

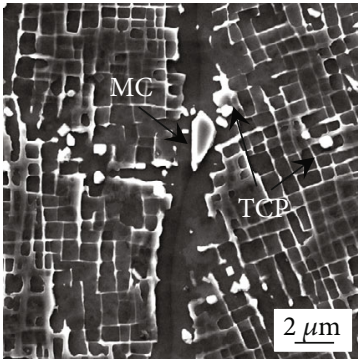

(c)

FIgURE 3: (a) SEM observation of the needle-like TCP phase in the bicrystal DD5 superalloy annealed at $950^{\circ} \mathrm{C}$ for $1000 \mathrm{~h}$. (b) SEM micrograph of three TCP morphologies (needle-like, short rod-like, and globular). (c) SEM micrograph of the globular TCP phase and MC carbide at the grain boundary.

phase channels of two adjacent grains and the angle between the secondary dendritic arms of two adjacent grains.

Figure 3 presents the morphologies of the TCP phase that precipitated in the bicrystal superalloy during long-term aging at $950^{\circ} \mathrm{C}$ for $1000 \mathrm{~h}$. As is shown in Figure 3(a), there was almost no TCP phase at the grain boundary, and a large number of needle-like TCP phases are parallel or perpendicular to each other precipitate on the dendrite. The needle-like TCP phases precipitate along the $<110>$ crystal direction on the $\{111\}$ crystal plane, and they are parallel or perpendicular to each other on the $\{001\}$ crystal plane. In addition, the angle between the needle-like TCP phases of two adjacent grains is about $21^{\circ}$. This is consistent with the results in Figure 2 . However, the direction of the needle-like TCP phase is not consistent with that of the $\gamma$ phase channel, but at an angle of $45^{\circ}$, as shown in Figure 3(b). The TCP phase is needle-like, short rod-like, and granular, as is shown in Figure 3(b). There are bigger MC carbides and small globular TCP phases at the grain boundary.

Figure 4 presents the morphologies of the TCP phase that precipitated near the grain boundaries during long-term aging at $950^{\circ} \mathrm{C}$. After aging for $100 \mathrm{~h}$, there is no any TCP phase that precipitated at the dendrites and grain boundary, and there is a large piece of the irregular $\gamma^{\prime}$ phase at the grain boundary, as shown in Figure 4(a). After aging for $500 \mathrm{~h}$, there is a small amount of needle-like TCP phases parallel or perpendicular to each other and small granular TCP at the dendrite, and there is no TCP phase that precipitated at the grain boundary, as shown in Figure 4(b). After aging for $1000 \mathrm{~h}$, a large number of needle-like TCP phases 


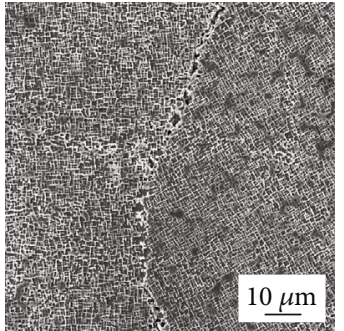

(a)

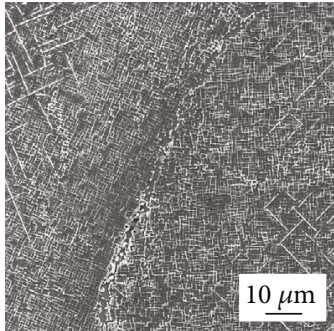

(b)

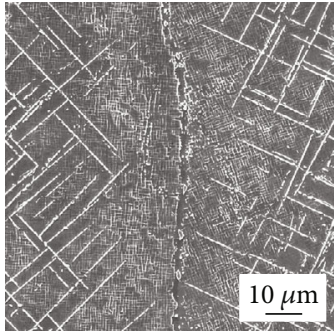

(c)

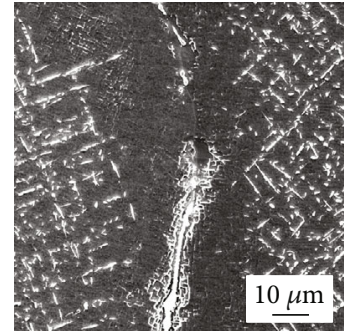

(d)

FIGURE 4: SEM micrographs of TCP phases in the grain boundaries annealed at $950^{\circ} \mathrm{C}$ for different hours: (a) $100 \mathrm{~h}$, (b) $500 \mathrm{~h},(\mathrm{c}) 1000 \mathrm{~h}$, and (d) $2000 \mathrm{~h}$

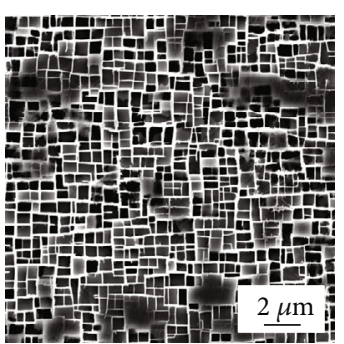

(a)

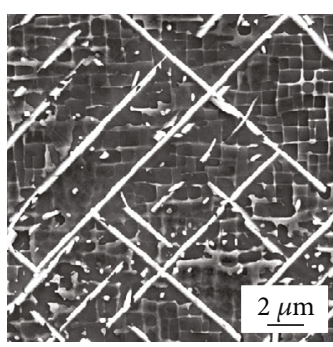

(b)

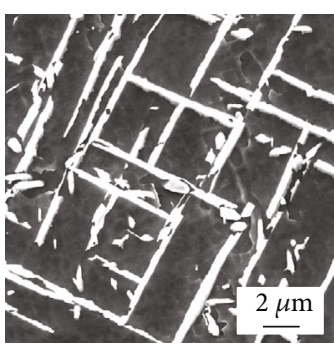

(c)

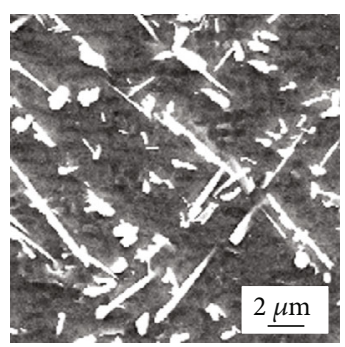

(d)

Figure 5: SEM micrographs of TCP phases in the dendrite trunks annealed at $950^{\circ} \mathrm{C}$ for different hours: (a) $100 \mathrm{~h}$, (b) $500 \mathrm{~h},(\mathrm{c}) 1000 \mathrm{~h}$, and (d) $2000 \mathrm{~h}$.

perpendicular to each other and big granular TCP appear at the dendrite and massive carbides begin to precipitate on the grain boundaries, as shown in Figure 4(c). After aging for $2000 \mathrm{~h}$, the needle-like TCP phase at the dendrite decomposes into granular and short rod-like phases, as shown in Figure 4(d).

Figure 5 shows the morphologies of the TCP phase that precipitated on the dendrite during long-term aging at $950^{\circ} \mathrm{C}$. After aging for $100 \mathrm{~h}$, there is no TCP phase that precipitated in the dendrite trunk, only the black $\gamma^{\prime}$ phase and white $\gamma$ phase, as shown in Figure 5(a), which is consistent with that of the low magnification of Figure 4(a). After aging for $500 \mathrm{~h}$, needle-like, granular, and short rod-like TCP phases precipitate at the dendrite trunk as shown in Figure 5(b). However, granular and short rod-like TCP phases are too small to be seen clearly; only the needle-like TCP phase can be seen in Figure 4(b). After aging for $1000 \mathrm{~h}$, the needle-like TCP phases begin to decompose and transform into granular and short rod-like ones, as shown in Figure 5(c). However, at low magnification (Figure 4(c)), granular and short rod-like TCP phases are too small to be seen clearly; only the needle-like TCP phase can be seen. After aging for $2000 \mathrm{~h}$, as shown in Figure 5(d), almost all needle-like TCP phases decompose into granular and short rod-like ones, which is consistent with that of the low magnification of Figure 4(d).

It can be derived from Figures 4 and 5 that with increasing aging time, the TCP phase gets coarser. This phenomenon is similar to the previous investigations $[24,25]$. The needle-like TCP phases first coarsened and then decomposed. The granular TCP coarsened first and then branched.

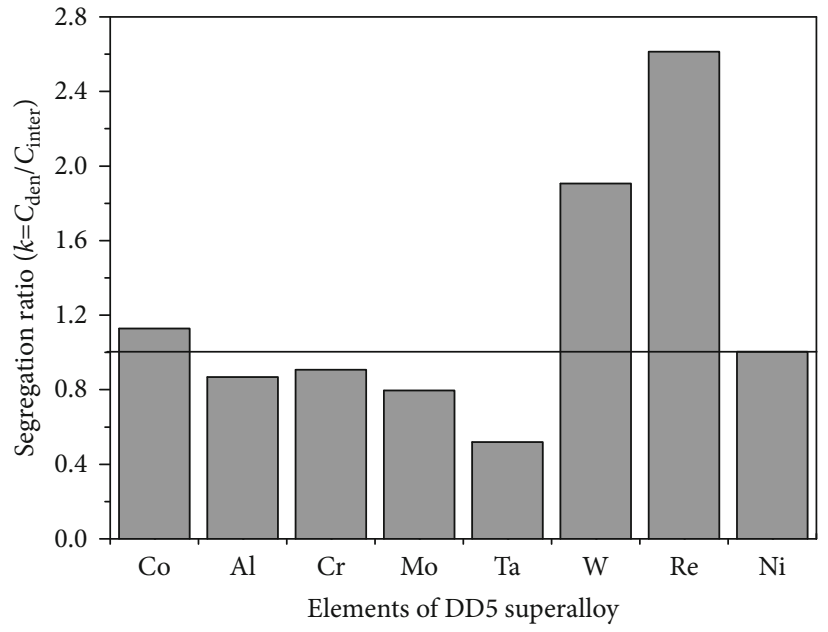

Figure 6: The element segregation of the as-cast DD5 superalloy.

It can be inferred from Figure 4 that TCP phases preferentially precipitate at the dendritic trunk, but it is difficult to precipitate at the interdendrite/grain boundary. This is caused by the segregation of the constituent elements of the TCP phase. The chemical composition of the TCP phase is made up of $\mathrm{Cr}, \mathrm{Mo}, \mathrm{W}$, and Re. For superalloy containing Re, the TCP phase usually has a high content of Re. The element segregation of the as-cast DD5 superalloy is shown in Figure 6. The segregation ratio of Re and $\mathrm{W}$ is 2.6 and 1.9 , respectively. The segregation ratio of $\mathrm{Cr}$ and $\mathrm{Mo}$ is 0.9 and 0.8 , respectively, which is close to 1 . The dendritic 
segregation of $\mathrm{W}$ and $\mathrm{Re}$ is serious, while the interdendritic segregation of $\mathrm{Cr}$ and $\mathrm{Mo}$ is not as intense as that for $\mathrm{W}$ and Re. In addition, the TCP phase contains more Re, so the TCP phase preferentially precipitates at the dendrite trunk.

\section{Conclusions}

(1) When the [001] crystallographic orientation of two adjacent grains is the same, the misorientation of the adjacent grains is not only the angle between the $\gamma$ phase channel of two adjacent grains but also the angle between the secondary dendrite arms of two adjacent grains. Although the direction of the needle-like TCP phase is not consistent with that of the $\gamma$ phase channel, but at an angle of $45^{\circ}$, the angle of the needle-like TCP phase of two adjacent grains is equal to the misorientation of two adjacent grains

(2) In the process of long-term aging, the needle-like TCP phase gradually decomposes and transforms into granular and short rod-like ones

(3) The TCP phases precipitate preferentially at the dendrite, but it is difficult to precipitate at the interdendrite/grain boundary, which is caused by the segregation of the constituent elements of the TCP phase to the dendrite

\section{Data Availability}

The data used to support the findings of this study are available from the corresponding author upon request.

\section{Conflicts of Interest}

The authors declare that they have no competing interests.

\section{Acknowledgments}

This work was supported by the Key Research and Development Program of Ningxia (2018BEE03017, 2019BDE03016), the Natural Science Foundation of Ningxia (2018AAC03250), and the Youth Science and Technology Talent Promotion Project of Ningxia (TJGC2019048).

\section{References}

[1] J. T. Guo, Superalloy Materials, Science Press, Beijing, China, 2008.

[2] A. K. Sinha, "Topologically Close-Packed Structures of Transition Metal Alloys," Progress in Materials Science, vol. 15, no. 2, pp. 81-185, 1972.

[3] R. Darolia, D. F. Lahrman, R. D. Field, and R. Sisson, "Formation of topologically closed packed phases in nickle base single crystal superalloys," in Superalloys 1988, pp. 255-264, TMS, Warrendale, 1988.

[4] C. M. F. Rae and R. C. Reed, "The precipitation of topologically close-packed phases in rhenium-containing superalloys," Acta Materialia, vol. 49, no. 19, pp. 4113-4125, 2001.
[5] F. C. Frank and J. S. Kasper, "Complex alloy structures regarded as sphere packings. I. Definitions and basic principles," Acta Crystallographica, vol. 11, no. 3, pp. 184-190, 1958.

[6] F. C. Frank and J. S. Kasper, "Complex alloy structures regarded as sphere packings. II. Analysis and classification of representative structures," Acta Crystallographica, vol. 12, no. 7, pp. 483-499, 1959.

[7] C. B. Shoemaker and D. Shoemaker, Developments in the Structural Chemistry of Alloy Phases, Plenum Press, 1969.

[8] S. Andersson, "Structures related to the $\beta$-tungsten or $\mathrm{Cr}_{3} \mathrm{Si}$ structure type," Journal of Solid State Chemistry, vol. 23, no. 1-2, pp. 191-204, 1978.

[9] K. H. Kuo, H. Q. Ye, and D. X. Li, “Tetrahedrally close-packed phases in superalloys: new phases and domain structures observed by high-resolution electron microscopy," Journal of Materials Science, vol. 21, no. 8, pp. 2597-2622, 1986.

[10] M. Simonetti and P. Caron, "Role and behaviour of $\mu$ phase during deformation of a nickel-based single crystal superalloy," Materials Science and Engineering: A, vol. 254, no. 1-2, pp. 1-12, 1998

[11] J. Zhu and H. Q. Ye, "On the microstructure and its diffraction anomaly of the $\mu$ phase in superalloys," Scripta Metallurgica et Materialia, vol. 24, no. 10, pp. 1861-1866, 1990.

[12] H. M. Tawancy, "Precipitation characteristics of $\mu$-phase in wrought nickel-base alloys and its effect on their properties," Journal of Materials Science, vol. 31, no. 15, pp. 3929-3936, 1996.

[13] X. Z. Qin, J. T. Guo, C. Yuan, G. X. Yang, L. Z. Zhou, and H. Q. Ye, " $\mu$-Phase behavior in a cast Ni-base superalloy," Journal of Materials Science, vol. 44, no. 18, pp. 4840-4847, 2009.

[14] K. Y. Cheng, C. Y. Jo, T. Jin, and Z. Q. Hu, "Precipitation behavior of $\mu$ phase and creep rupture in single crystal superalloy CMSX-4," Journal of Alloys and Compounds, vol. 509, no. 25, pp. 7078-7086, 2011.

[15] K. Zhao, L. H. Lou, Y. Wen, H. Li, and Z. Q. Hu, "Nucleation and growth of $\mu$ phase," Journal of Materials Science, vol. 39, no. 1, pp. 369-371, 2004.

[16] P. A. Carvalho, H. S. D. Haarsma, B. J. Kooi, P. M. Bronsveld, and J. T. M. De Hosson, "HRTEM study of $\mathrm{Co}_{7} \mathrm{~W}_{6}$ and its typical defect structure," Acta Materialia, vol. 48, no. 10, pp. 2703-2712, 2000.

[17] P. A. Carvalho and J. T. M. De Hosson, "Stacking faults in the $\mathrm{Co}_{7} \mathrm{~W}_{6}$ isomorph of the $\mu$ phase," Scripta Materialia, vol. 45, no. 3, pp. 333-340, 2001.

[18] K. Hiraga, T. Yamamoto, and M. Hirabayashi, "Intermetallic compounds of the $\mu$ - and P-phases of $\mathrm{Co}_{7} \mathrm{Mo}_{6}$ studied by 1 MV electron microscopy," Transactions of the Japan Institute of Metals, vol. 24, no. 6, pp. 421-428, 1983.

[19] Y. Qiao, D. Xu, S. Wang et al., "Corrosion and tensile behaviors of $\mathrm{Ti}-4 \mathrm{Al}-2 \mathrm{~V}-1 \mathrm{Mo}-1 \mathrm{Fe}$ and $\mathrm{Ti}-6 \mathrm{Al}-4 \mathrm{~V}$ titanium alloys," Metals, vol. 9, no. 11, p. 1213, 2019.

[20] A. Sato, H. Harada, T. Yokokawa et al., "The effects of ruthenium on the phase stability of fourth generation Ni-base single crystal superalloys," Scripta Materialia, vol. 54, no. 9, pp. 1679-1684, 2006.

[21] Y. Qiao, J. Chen, H. Zhou et al., "Effect of solution treatment on cavitation erosion behavior of high-nitrogen austenitic stainless steel," Wear, vol. 424-425, pp. 70-77, 2019.

[22] L. Wang, J. Shen, Y. Zhang, and H. Fu, "Microstructure, fracture toughness and compressive property of as-cast and 
directionally solidified NiAl-based eutectic composite," Materials Science and Engineering A, vol. 664, pp. 188-194, 2016.

[23] L. Wang and J. Shen, "Effect of withdrawal rate on the microstructure and room temperature mechanical properties of directionally solidified NiAl-Cr(Mo)-(Hf, Dy)-4Fe alloy," Journal of Alloys and Compounds, vol. 663, pp. 187-195, 2016.

[24] L. Wang, J. Shen, G. Zhang et al., "Stability of lamellar structure of directionally solidified NiAl-28Cr-6Mo eutectic alloy at different withdrawal rates and temperatures," Intermetallics, vol. 94, pp. 83-91, 2018.

[25] L. Wang, G. Zhang, J. Shen et al., "A true change of $\mathrm{NiAl}-\mathrm{Cr}(\mathrm{Mo})$ eutectic lamellar structure during high temperature treatment," Journal of Alloys and Compounds, vol. 732, pp. 124-128, 2018. 